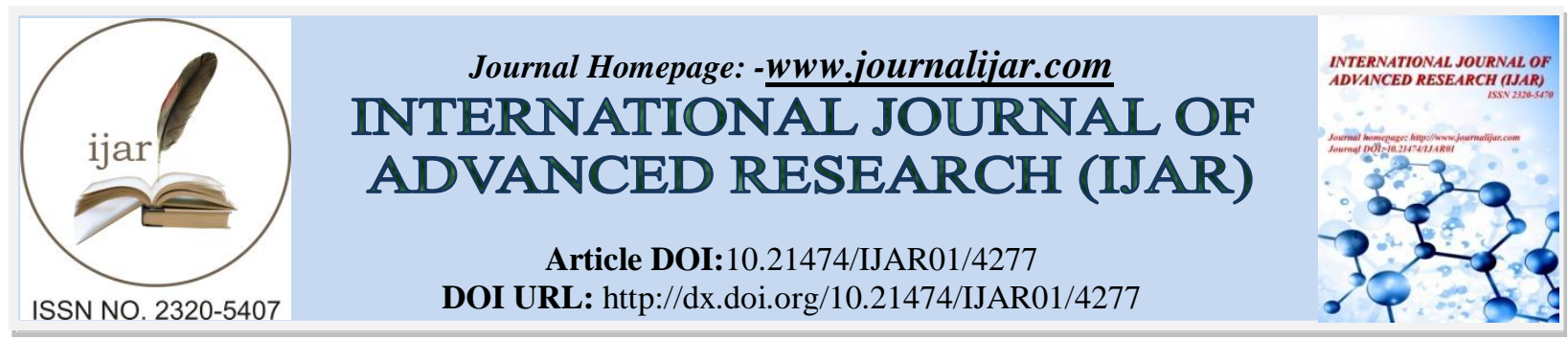

RESEARCH ARTICLE

\title{
PREVALENCE OF ANAEMIA AND HAEMOGLOBINOPATHIES AMONG COLLEGE STUDENTS OF RAJKOT, GUJARAT.
}

\author{
Vachhani Nishith, Nandani Sanjeev and Vekariya Daya. \\ Indian Medical Scientific Research Foundation, Life Blood Centre, 24-Vijay Plot, Samir Dholakiya Marg, Malaviya \\ Road, Rajkot - 360002, Gujarat, India.
}

\section{Manuscript Info}

Manuscript History

Received: 28 March 2017

Final Accepted: 30 April 2017

Published: May 2017

Key words:-

Anaemia, Haemoglobinopathies,

Thalassaemia Carrier, NESTROFT,

HPLC

\begin{abstract}
In India, major cause of anaemia is nutritional deficiencies which can be treated by medications. Haemoglobinopathies are the most common inherited red cell disorders world-wide. Most clinically significant haemoglobinopathies are inherited defects of the beta $(\beta)$ globin chain of adult haemoglobin.Nutritional anaemia affects all age and sex groups in India. Iron deficiency anaemia is the most common micronutrientdeficiency in the world affecting more than 2 billion persons. The Present study is an attempt to assess the prevalence of anaemia and haemoglobinopathies among college students in order to sensitize the masses about its impacts. 650 college students in the age group of 16-28 years of Rajkot, Gujarat were the subjects of study. Haemoglobin estimation was performed by automated cell counter and observations were interpreted as per WHO criteria. The study showed that $17.69 \%$ were affected with various grades of anaemia condition. $11.69 \%$ subjects being mildly anaemic and5.85\% moderatelyanaemic while $0.15 \%$ suffered from severe anaemia. Various haemoglobinopathies were also studied by screening method NESTROFT and confirmed by HPLC method. Prevalence of Beta thalassaemia carrier was $3.54 \%$. Beta-thalassemia continues to be a cause of significant burden tothe society particularly in the developing countries. Further studies with a large sample size are needed to draw out theexact proportion for prevalence of anaemia and haemoglobinopathies so that appropriate remedial measures can be taken.
\end{abstract}

Copy Right, IJAR, 2017,. All rights reserved.

\section{Introduction:-}

Health, nutrition and population policies play apivotal role in economic and human developmentand in poverty alleviation. Nutrition will remain a keyelement in ensuring security: adequate foodis literally "vital" in keeping people alive as abasic need and human right. ${ }^{(23)}$ The prevalence of anaemia is an important healthindicator for the country like India. ${ }^{(7)}$ Anaemia, defined as a low blood haemoglobin concentration(andconsequently their oxygencarrying capacity) is insufficient to meet the body's physiologic needs and it has been shown to be a public health problemthat affects low, middle and high-income countries and has significant adverse health consequences, as well as adverse impacts on social and economic development. Specific physiologic needs vary with a person'sage,

Corresponding Author:-Vachhani Nishith.

Address:-Indian Medical Scientific Research Foundation, Life Blood Centre, 24-Vijay Plot,Samir 1532 
gender, residential elevation above sea level (altitude), smokingbehaviour, and different stages of pregnancy. Anaemia may result from a number of causes, with the most significant contributor being iron deficiency. ${ }^{(7)}$

The World Health Organization (WHO) global estimates of anaemia prevalence averaged 56\%, with a range of 35$75 \%$ depending on the geographic location. Anaemia affects approximately 30-55\% of young adults all over the world.South Asia has the highest prevalence of anaemia in the world, which is attributed to high rates of malnutrition. ${ }^{(8)}$ In South-East Asia region of WHO, mean haemoglobin concentration $10.7 \mathrm{gm} \%$ (10.4 to $11.2 \mathrm{gm} \%$ ) and $53.8 \%$ (39.9 to $63.9 \%$ ) of population is suffering with anaemia. ${ }^{(21)}$ Women of childbearing age are having an additional riskof developing anaemia because of their monthly menstrualblood loss and nearly 50 percent of females in this age groupare anaemic. On average a healthy woman loses about $25-30 \mathrm{ml}$ of blood monthly. Therefore, the body needs toproduce blood in order to compensate for this loss and if theessential nutrients required for haemopoiesis are not suppliedin their diet, anaemia will develop. ${ }^{(1)}$

Correcting anaemia requires an integrated approach based on identifying and addressing the contributingfactors. Low blood haemoglobin concentrations may be caused by genetic traits like sickle cell andthalassaemias; inadequate bioavailable dietary iron, folic acid and/or vitamin B-12; malaria, schistosomiasis, hookworm or human immunodeficiency virus (HIV) infections; and some noncommunicable diseases. ${ }^{(21)}$

Approximately $50 \%$ of cases of anaemia areconsidered to be due to iron deficiency, but the proportion probably varies among population groupsand in different areas, according to the local conditions. Anaemia resulting from iron deficiency adversely affects cognitive and motor development, causesfatigue and low productivity and, when it occurs in pregnancy, may be associated with low birthweight and increased risk of maternal and perinatal mortality. ${ }^{(21)}$

Iron deficiency anaemia (IDA) and beta thalassemia trait $(\beta$-TT) are the commonest hematological abnormalities presenting with mild microcytic anaemia.Deficiency of elemental iron in diet accounts for the commonest hematological disorder in the form of IDA with approximately $30 \%$ of the world population (with majority in third world countries) suffering from it. In contrast, a common mimicker of microcytic anaemia which often confounds a diagnosis of IDA (nutritional case) in third world countries is thalassemia syndrome (trait) which is seen in $3 \%$ of the population. The main patho-physiology of these syndromes is absence / lack of either alpha or beta globin chains resulting in alpha or beta thalassaemia respectively. ${ }^{(17)}$

The inherited hemoglobin $(\mathrm{Hb})$ disorders are the most commonsingle gene defect in man. Theprevalence of haemoglobinopathies is on therise worldwide. This is of special importancein developing countries where it increasesthe burden of health care delivery system. The abnormalities can either be quantitative(the thalassemia syndromes) or qualitative(the hemoglobin variants) or a combinationof both. ${ }^{(3)}$

Of these, the thalassemia syndromesparticularly the beta thalassemia and somealpha thalassemia are the major cause ofmorbidity. It is estimated that $1.5 \%$ ofthe world's population are carriers of betathalassemia- that is, at least there are 80million to 90 million people with an estimated60,000 new cases being born each year. TheSouth-east Asia region (which includes India,Thailand and Indonesia) accounts for 50\% ofworld carriers. In India, nearly 30 millionpeople are carriers of beta thalassemia and 7000 babies with beta-thalassemia major areborn every year. The carrier rate variesbetween 0 to $17 \%$ in different ethnic groups. ${ }^{(3)}$

Thalassemia is an autosomal recessive inherited group ofdisorders of hemoglobin synthesis characterized by theabsence or reduction of one or more of the globin chains ofhemoglobin. The structural variants result from substitutionof one or more amino acids in the globin chains of thehemoglobin molecule. Being recessivelyinherited from the parents, the thalassemia and thalassemichaemoglobinopathies pose serious health problem leading tosevere morbidity and mortality in Indian population. With increasing global awareness and mass screeningprograms undertaken at various levels by health care system, the responsibility for laboratory personnel has greatlyenhanced in detection and prevention of this problem.Awareness about the diagnostic problems as well as theirsolutions is very important so that one does not miss a singlecase. ${ }^{(15)}$

\section{Materials and methods:-}

A cross sectional survey of college going students was conducted to rule out the status of base line anaemia prevalence and to differentiate types of haemoglobinopathy at Rajkot, Gujarat, INDIA.A total of 650 students of 
both the sex were enrolled in thisstudy. All students' ages ranged between 16 to 28 years.A consent form along with an information sheet givingdetails of the study (nature of the study, what will be expectedfrom the participants, and expected risks and benefits) wereprovided to all students who were randomlyselected to the sample. The details were also explainedverbally to the potential participants.

A total volume of $2 \mathrm{ml}$ of venous blood was obtainedfrom each participant into EDTA(ethylenediaminetetraaceticacid) containers for CBC analysis, NESTROFT test and HPLCto classify the type ofanaemia and haemoglobinopathies. Bloodwas drawn by skilled personal. Universal precautions werefollowed during blood collection, transportation, storage, anddisposal to protect the participants as well as the researchers. The blood samples were mixed onelectric blood mixture for 8 to 10 minutes andthereafter analyzed on the Sysmex XP100, three part differential cell counterto obtain the hemoglobin values and indices as described in theinstruction manual. Mentzer index (MCV/RBC) was also used for screening of thalassaemia carrier. All samples were analyzed by NESTROFT method as a primary screening test. All NESTROFT positive samples were reanalyzed on the BioRad Variant-II HPLCsystem (BioRad Laboratories, USA) as described in theinstruction manual.

Naked-Eye-Single-Tube-RedCell-Osmotic-Fragility-Test as its name implies, is used to assess osmotic fragility of red cells at a single concentration of buffered saline $(0.36 \%$ in single tube) visually without a spectrophotometer. A stock solution of $10 \%$ buffered saline $(\mathrm{pH} 7.4)$ is prepared by taking $\mathrm{NaCl} 90 \mathrm{gm}, \mathrm{Na} 2 \mathrm{HPO} 413.655$ gm and $\mathrm{NaH} 2 \mathrm{PO} 4,2 \mathrm{H} 202.4 \mathrm{gm}$ and dissolving them in 1 litre of distilled water. From this, a litre of 1 buffered saline is prepared by 1:10 dilution with distilled water. $0.36 \%$ buffered saline is prepared by diluting $36 \mathrm{ml}$ of $1 \%$ buffered saline with $64 \mathrm{ml}$ distilled water to make $100 \mathrm{ml} .2 \mathrm{ml}$ of $0.36 \%$ buffered saline is taken in one tube $(10 \mathrm{~cm} \mathrm{x} 1 \mathrm{~cm}$ diameter) and $2 \mathrm{ml}$ distilled water is taken in another. A $20 \mu \mathrm{l}$ of blood is added to each of the tubes, which are left undisturbed for half an hour at room temperature. After half an hour the contents of both the tubes are shaken and the tubes held against a white paper on which a thin black line is drawn. ${ }^{(9)}$

Interpretation of NESTROFT results:The line is clearly visible through the contents of the tube containing distilled water due to complete lysis. If the line is visible through the contents of the tube with buffered saline, the test is negative, whereas if the line is not visible, the test is positive. The tubes are then left undisturbed for a few hours. At the end of this period, contents of thetube with distilled water remain uniformly pink with no sediment at the bottom. In the case of a negative test, the tube containing buffered saline also presents a similar picture. With a positive test, the tube shows sediment of the red cells at the bottom and the top part of the saline is colourless. This is an additional confirmatory evidence of a test earlier interpreted as positive. ${ }^{(9)}$

A positive NESTROFT indicates that all red cells in the tested sample have not undergone lysis in $0.36 \%$ buffered saline. These unlysed red cells result in the hazy appearance of the contents of the tube and render the line on the paper indistinct. These red cells also sediment as a button at the bottom of the tube when it is left undisturbed for some time. Thus a positive NESTROFT indicates decreased red cell osmotic fragility and increased resistance to osmotic lysis.HbA2 was performed in all NESTROFT positive subjects to compute sensitivity of the NESTROFT. ${ }^{(9)}$ The Variant-II Beta Thalassaemia Short Programutilizes principles of ion-exchange highperformanceliquid chromatography (HPLC). The samples are automaticallymixed and diluted on the Variant-II Sampling Station(VSS) and injected to the analytical cartridge. The Variant-II Chromatographic Station (VCS) dual pumps deliver aprogrammed buffer gradient of increasing ionic strength tothe cartridge, where HbA2/F are separated based on theirionic interaction with the cartridge material. The separatedHbA2/F then pass through the flow cell of the filter photometerwhere the changes in absorbance at $415 \mathrm{~nm}$ are measured.An additional filter at $690 \mathrm{~nm}$ corrects the backgroundabsorbance.The Variant-II CDM (CDM) Software performsreduction of raw data collected from each analysis. To aid inthe interpretation of results, windows have been establishedfor the most frequently occurring hemoglobins based on thecharacteristic retention time. For each sample, a sample reportand a chromatogram are generated by CDM showing allhemoglobin fractions eluted, their retention times, the areaof the peaks, and values of the fractions.Reports and chromatogramsgenerated were studied and interpreted by observing $\mathrm{HbA} 2$ and $\mathrm{F}$ concentration for beta thalassemia and retentiontime and area percentage of other peaks and windows forstructural variants. Each chromatogram shows peaks of $\mathrm{HbA} 0, \mathrm{HbA} 2$ andHbF alongwith $\mathrm{C}$-window, D-window, S-window and two minor peaks, P2 and P3. Several hemoglobin variantselute same window; they were provisionally diagnosed byretention time and area percentage keeping in mind theethnicity of the patients.Other relevant tests were done, for example, Sickling test (using sodium meta bisulphite) when D-window or/and Swindow was eluted in the sample. ${ }^{(18)}$ 


\section{Results:-}

The anaemia was observed in 115 (17.69\%) students out of total 650 (396 male and 254 female) students selected to carry out study from college in Rajkot. The mean of haemoglobin among students was $13.79 \mathrm{gm} \%$ (14.71 gm\% in male and $12.34 \%$ in female). The prevalence of anaemia in male students was $6.82 \%$ and $34.65 \%$ in female students [Table-1]. As per haemoglobin concentrations for the diagnosis of anaemia and assessment of severity by World Health Organization, we observed there were mild anaemia among 76 students (11.69\%), moderate anaemia among 38 students $(5.85 \%)$ followed by severe anaemia in 1 female student $(0.15 \%)$ [Table-2]. Among 650 study samples for NESTROFT, 75 (11.54\%) were detected with positive findings [Table-3]. Total 77 samples (75 screening positive in NESTROFT + 2 abnormal indices in haemogram) were analyzed by high performance liquid chromatography (HPLC) on Variant-II (Bio-Rad Laboratories, USA) for haemoglobin fractionation study. Total 23 $(3.54 \%)$ were diagnosed Beta thalassaemia trait and $8(1.23 \%)$ were identified with other haemoglobinopathies [Table-4].

Table1:-Sex-wise distribution of anaemia

\begin{tabular}{|c|c|c|c|}
\hline Anaemia & Male (\%) & Female (\%) & Total (\%) \\
\hline Present & $27(6.82)$ & $88(34.65)$ & $115(17.69)$ \\
\hline Absent & $369(93.18)$ & $166(65.35)$ & $535(82.31)$ \\
\hline Total & $396(100)$ & $254(100)$ & $650(17.69)$ \\
\hline
\end{tabular}

Table 2:-Severity of anaemia among students

\begin{tabular}{|c|c|c|c|}
\hline Severity & Male (\%) & Female (\%) & Total (\%) \\
\hline Mild & $22(5.56)$ & $54(21.26)$ & $76(11.69)$ \\
\hline Moderate & $5(1.26)$ & $33(12.99)$ & $38(5.85)$ \\
\hline Severe & 0 & $1(0.39)$ & $1(0.15)$ \\
\hline
\end{tabular}

Table 3:-Screening test results of NESTROFT

\begin{tabular}{|c|c|c|c|}
\hline Result & Male & Female & Total (\%) \\
\hline Positive & 36 & 39 & $75(11.54)$ \\
\hline Negative & 360 & 215 & $575(88.46)$ \\
\hline Total & 396 & 254 & $650(100)$ \\
\hline
\end{tabular}

Table 4:-Pattern of Haemoglobinopathies by HPLC method

\begin{tabular}{|l|c|}
\hline \multicolumn{1}{|c|}{ Result } & Number (\%) \\
\hline Beta Thalassaemia Trait & $23(3.54)$ \\
\hline DeltaBeta Thalassaemia Trait & $1(0.15)$ \\
\hline Hereditary Persistence of Fetal Hemoglobin heterozygous & $1(0.15)$ \\
\hline Hereditary Persistence Fetal Hemoglobin/ Delta Beta Thalassaemia Trait. & $1(0.15)$ \\
\hline $\begin{array}{l}\text { Homozygous for Hb D Punjab/ Double heterozygous for Hb D Punjab \& Beta } \\
\text { Thalassaemia Trait }\end{array}$ & $1(0.15)$ \\
\hline Hb D (Punjab) Trait & $1(0.15)$ \\
\hline Sickle Cell Trait & $1(0.15)$ \\
\hline Borderline for Beta Thalassaemia Trait. & $2(0.31)$ \\
\hline Total & $32(4.77)$ \\
\hline
\end{tabular}

\section{Discussion:-}

Globally, the mean blood haemoglobin concentration was 11.1 gm\% (95\% credibility interval [CI]: 11.0-11.3) inchildren, $12.6 \mathrm{gm} \%$ (95\% CI: 12.4-12.8) in non-pregnant women, and $11.4 \mathrm{gm} \%$ (95\% CI: 11.2-11.6) in pregnantwomen, indicating that, on average, all population groups were above the threshold formild anaemia (11.0 gm\% for children and pregnant women and $12.0 \mathrm{gm} \%$ for non-pregnant women). ${ }^{(21)}$ In India, the mean blood haemoglobin concentration is $11.9 \mathrm{gm} \%$ (95\% CI: 11.3-12.5) in non-pregnant women. ${ }^{(21)}$ In present study the average haemoglobin concertation in non-pregnant women was $12.34 \mathrm{gm} \%$ which falls in WHO data. ${ }^{(21)}$ On the basis of the WHO cut-offs points, in this study, anaemia prevalence in this study population was $17.69 \%$. The prevalence of anaemia was $34.65 \%$ for women, whereas only $6.82 \%$ of the men were anemic.Chaudhary S. et. al. carriedout a study in an urban area under Urban HealthTraining Center of a medical college, Nagpur, among atotal of 296 
adolescent females (10-19 years old) andaccording their observations the prevalence of anaemiawas found to be $35.1 \%{ }^{(5)}$

Haemoglobinopathies are prevalent worldwide,but it is more prevalent in some geographicalareas. The distribution of beta thalassemia is notuniform in the Indian subcontinent. Thoughcertain communities are identified to have highprevalence, it has been detected in almost everyIndian population. The haemoglobinopathies andthalassemia are the most common inheritedsingle gene disorder in India. Therefore there isalways a need for a screening method which candetect maximum variants. ${ }^{(13)}$ The prevalence of betathalassemia trait varies from $1-17 \%$ in differentpopulations of India. ${ }^{(18)}$ According to study done by Indian Red Cross society, Gujarat State Branch, prevalence of beta thal trait is $3.4 \%$ in Ahmedabad Gujarat. ${ }^{(2)}$ In our data, the prevalence of thalassaemia trait is $3.54 \%$.

\section{Conclusion:-}

Reducing anaemia is recognized as an important component of the health of women and children, and thesecond global nutrition target for 2025 calls for a 50\% reduction of anaemia in women of reproductiveage by World Health Organization. Iron deficiency anaemia should ideally be addressed through dietary diversificationand improved access to foods that have high levels of bioavailable iron, including animal products. Dailyor intermittent iron supplementation, alone or together with folic acid and other micronutrients, can beused for high-risk groups (children, pregnant women and women of reproductive age), to improve ironintakes. Other food basedapproaches, such as fortification of staple foods and condiments can also be used to improve ironintake in the general population. Fortification of wheat flour with iron and other vitamins andminerals is currently mandated in 80 countries but the extent of coverage varies.In India, the prevalence of anaemia remains high and is an area of priority. If thecurrent trends are maintained, there is a probability of less than $25 \%$ in all regions of reaching theglobal target of reducing the prevalence of anaemia by $50 \%$ in women of reproductive age. To make asignificant impact, it is likely that a combination of key programmes that address the determinants of lowblood haemoglobin concentrations will be required. These strategies should be tailored to local conditions,taking into account the specific etiology and prevalence of anaemia in a given setting and populationgroup, and should be built into the primary health-care system and existing programmes.

NESTROFT is reliable, cost effective and better screening test for thalassaemia carrier detection. Positive cases can be confirmed by HPLC. NESTROFT can be used in mass haemoglobinopathies screening programmes.

Mass awareness programmes, anaemia screening programmes, integrated planning, multi-sectoral approach, community support along with anaemia prevention and treatment should be initiated for betterment of youth of India.

\section{References:-}

1. Al-Sayes et. al. "Prevalence of iron deficiency and iron deficiency anemia among females at university stage." Journal of Medical Laboratory and Diagnosis 2, no. 1 (2011): 5-11.

2. Bhalodia Jignasha et. al. "Study of hemoglobinopathies in patients of anemia using high performance liquid chromatography (HPLC) in Western India." Community Med 6, no. 1 (2015): 35-40.

3. ChakrabartiIndranilet. al. "Beta-Thalassemia Carrier Detection by NESTROFT: An Answer in Rural Scenario?" Iranian Journal of Pathology 7, no. 1 (2012): 19-26.

4. Chandrahas Prasad et. al. "Naked Eye Single Tube Red Cell Osmotic Fragility Test Screening For Detection Of B-Thalassemia Trait - An Evaluation Against HPLC Method At Rajendra Institute Of Medical Sciences, Ranchi" Research Journal of Pharmaceutical, Biological and Chemical Sciences July-Aug, 2014, 5(4) 13881396.

5. Chaudhary Sanjeev M.et. al. "A study of anemia among adolescent females in the urban area of Nagpur." Indian journal of community medicine: official publication of Indian Association of Preventive \& Social Medicine 33, no. 4 (2008): 243.

6. Colah, R. B. et. al. "HPLC studies in hemoglobinopathies." The Indian Journal of Pediatrics 74, no. 7 (2007): 657-662.

7. Haemoglobin concentrations for the diagnosis of anaemia and assessment of severity. WHO WHO/NMH/NHD/MNM/11.1 
8. Hanafi et. al. "Study of hemoglobin level and body mass index among preparatory year female students at Taibah University, Kingdom of Saudi Arabia." Journal of Taibah University Medical Sciences 8, no. 3 (2013): 160-166.

9. Himaxi Rathodet. al. "NESTROFT AS A SCREENING TEST FOR BETA THALASSEMIA" Int. J. of Adv. Res. 2 (8).

10. Kabiret. al. "A Screening Test for Iron Deficiency Anaemia and Thalassaemia Traits." Journal of Bangladesh College of Physicians \& Surgeons 32, no. 4 (2014): 190.

11. Mehta, Kamal. "Prevalence of Nutritional Anaemia among College Students and its Correlation with their Body Mass Index." Journal of Bangladesh College of Physicians and SurgeonsVol. 32, No. 4, October 2014.

12. Moscaet. al. "The role of haemoglobin A2 testing in the diagnosis of thalassaemias and related haemoglobinopathies." Journal of Clinical Pathology 62, no. 1 (2009): 13-17.

13. Nigam N. et. al. "HPLC as a classical tool for screening of $\beta$-Thalassemia and Hemoglobinopathies in Kanpur" Rama Univ. J. Med Sci 2015;1(1):6-9.

14. Pandey Sachin et. al. "A cross sectional study of nutritional anemia among medical students in a medical college, at Bilaspur, Chhattisgarh." National Journal of Medical Research 3, no. 2 (2013): 143-146.

15. Pant Leela et. al. "Detection of abnormal hemoglobin variants by HPLC method: common problems with suggested solutions." International Scholarly Research Notices 2014 (2014).

16. Patel A. P. et. al. "Prevalence of common hemoglobinopathies in Gujarat: An analysis of a large screening programme." Natl J Community Med 3 (2012): 112-6.

17. Piplani Sanjay et. al. "NESTROFT-A Valuable, Cost Effective Screening Test for Beta Thalassemia Trait in North Indian Punjabi Population." Journal of clinical and diagnostic research: JCDR 7, no. 12 (2013): 2784.

18. Sachdev et. al. "Detection of $\mathrm{Hb}$ variants and hemoglobinopathies in Indian population using HPLC: report of 2600 cases." Indian journal of pathology and microbiology 53, no. 1 (2010): 57.

19. Sharma Gopikishan et. al. "Use of NESTROFT as a screening test for the carriers of thalassemia major." Pediatric Review: International Journal of Pediatric Research 3, no. 07 (2016).

20. Sharma Santanu K. et. al. "Haemoglobinopathies-major associating determinants in prevalence of anaemia among adolescent girl students of Assam, India." (2012). WHO South-East Asia Journal of Public Health 2012;1(3):299-308.

21. The global prevalence of anaemia in 2011 - WHO 2015.

22. WHO Global Database on Anaemia - Worldwide prevalence of anaemia 1993-2005.

23. WHO Regional strategy on nutrition 2010-2019 and Plan of action. WHO-EM/NUT/256/E. 